\title{
ENRAIZAMENTO DE ESTACAS HERBÁCEAS DE MIRTILO: INFLUÊNCIA DA LESÃO NA BASE E DO ÁCIDO INDOLBUTÍRICO
}

\author{
Rooting of herbaceous blueberry cuttings: influence of the base incision and indolbutiric acid
}

\author{
Renato Trevisan', Rodrigo Cezar Franzon ${ }^{2}$, Roberto Fritsche Neto ${ }^{3}$, \\ Rafael da Silva Gonçalves ${ }^{4}$, Emerson Dias Gonçalves ${ }^{5}$, Luis Eduardo Corrêa Antunes ${ }^{6}$
}

\begin{abstract}
RESUMO
O mirtilo (Vaccinium sp.) é uma espécie de clima temperado que, por ocasião do período vegetativo, produz abundante quantidade de material vegetal que pode ser utilizado na propagação. Objetivou-se verificar o potencial de enraizamento de estacas herbáceas de diferentes cultivares de mirtilo, tratadas ou não com ácido indolbutírico e com e sem lesão na base. O trabalho foi realizado em dois experimentos, testando a capacidade de enraizamento das cultivares Florida, Woodard, Bluegem, Bluebele, Clímax e Briteblue. No primeiro experimento, as estacas das cultivares foram tratadas com AIB $\left(0,2500,5000\right.$ e $\left.7500 \mathrm{mLL}^{-1}\right)$. No segundo experimento utilizou-se $2000 \mathrm{mgL}^{-1}$ de AIB, em estacas com e sem lesão na base. O delineamento utilizado foi completamente casualizado com repetições e unidades experimentais adequadas para cada experimento. $\mathrm{O}$ uso do ácido indolbutírico e a lesão nas estacas, não proporcionaram estímulo na emissão de raízes adventícias; as cultivares apresentam potencial genético de enraizamento diferenciado, sendo que, a Bluebelle apresentou maiores porcentuais de estacas enraizadas, e a Clímax, os menores porcentuais.
\end{abstract}

Termos para indexação: Propagação vegetativa, estaquia, mirtilo, Vaccinium sp.

\section{ABSTRACT}

Blueberries (Vaccinium sp.) are species of temperate climate that, for occasion of the vegetative period, produce large amount of vegetal material that can be used in the propagation. This way, with the aim of verifying the rooting potential of different herbaceous cuttings of blueberry cultivars, with the use or not of indolbutíric acid and base injury. The work was carried out in two experiments, having tested the capacity of rooting of the following cultivars Florida, Woodard, Bluegem, Bluebele, Clímax and Briteblue. In the first experiment, cuttings of cultivars were treated with IBA $\left(0,2500,5000\right.$ and $\left.7500 \mathrm{mg} . \mathrm{L}^{-1}\right)$. On the second experiment one used $2000 \mathrm{mg} . \mathrm{L}^{-1}$ of $\mathrm{AIB}$, in cuttings with and without injury in the base. The experimental design was the completely randomized with adjusted repetitions and experimental units for each experiment. After 90 days, it was evaluated rooting percentage for each cultivar submitted to IBA treatment with different doses. The use of the indolbutíric acid and the cutting injury, did not stimulated the emission of adventitious root; the cultivars present genetic potential of differentiated rooting, so that, the Bluebelle presented higher percentage rooting cutting, and the Climax, the lowest percentage.

Index terms: Vegetative propagation, cuttings, blueberry, Vaccinium sp.

(Recebido em 27 de outubro de 2006 e aprovado em 4 de dezembro de 2007)

\section{INTRODUÇÃO}

O mirtilo é nativo da América do Norte, Estados Unidos e Canadá. Na América do Sul, Chile, Argentina e Uruguai, são os maiores produtores. Em 2003 produziram cerca de $11 \%$ da produção mundial. O Brasil, nesse período apresentou uma área de 25ha (STRICK, 2005), sendo relativamente baixa, se comparada aos demais países sulamericanos. Um dos motivos pela pequena área explorada pela cultura é a falta de mudas em quantidade e em qualidade, pois a cultura é altamente rentável.

$\mathrm{Na}$ maioria das plantas frutíferas, a propagação é realizada pelo método de estaquia, que, além de proporcionar muda de qualidade, fixa características agronômicas desejáveis de forma eficiente (BASTOS et al., 2005). A propagação do mirtilo se dá basicamente através de estaquia, embora com resultados variáveis e insatisfatórios (MAINLAND, 1966). Por outro lado, a

\footnotetext{
${ }^{1}$ Engenheiro Agrônomo, Doutor - Embrapa Clima Temperado - BR 392, Km 78 - Cx. P. 403 - 96001-970 - Pelotas, RS - renatrevisan@gmail.com Bolsista EV CNPq

'Engenheiro Agrônomo, Doutorando - Faculdade de Agronomia Eliseu Maciel/FAEM - Universidade Federal de Pelotas/UFPel - Campus Universitário, s/n - Cx. Postal 354 - 96010-900 - Pelotas, RS - rcfranzon@hotmail.com - Bolsista CAPES.

${ }^{3}$ Engenheiro Agrônomo, Mestrando - Departamento de Genética - Escola Superior de Agricultura Luiz de Queiroz/ESALQ - Avenida Pádua Dias, 11 - Cx. P. 83 - 13400-970 - Piracicaba, SP - rfneto@esalq.usp.br

${ }^{4}$ Graduando em Agronomia - Faculdade de Agronomia Eliseu Maciel/FAEM - Universidade Federal de Pelotas/UFPel - Campus Universitário, s/n - Cx Postal 354 - 96010-900 - Pelotas, RS - rsgagro@pop.com.br

${ }^{5}$ Engenheiro Agrônomo, Doutor - Fazenda de Maria da Fé/FEMF - Empresa de Pesquisa Agropecuária de Minas Gerais/EPAMIG - Vargedo - $35517-000$ Maria da Fé, MG - emersondg@gmail.com

${ }^{6}$ Engeneiro Agrônomo, Doutor - Embrapa Clima Temperado - BR 392, Km 78 - Cx. P. 403 - 96001-970 - Pelotas, RS - antunes@cpact.embrapa.br
} 
micropropagação proporciona resultados significativos, entretanto, essa técnica é de custo elevado e exige condições especiais na produção e formação das mudas.

Vários fatores, tanto endógenos como exógenos, influenciam na capacidade de enraizamento de diferentes espécies vegetais, entre os quais o tipo de substrato, uso de reguladores de crescimento exógenos, fatores ambientais, idade da planta, condição fisiológica da planta matriz, tipo de estaca, época de estaquia e ação dos agentes oxidantes próprios de cada planta (CHALFUN \& HOFFMANN, 1997).

$\mathrm{Na}$ estaquia, muitas vezes, a aplicação de reguladores de crescimento é decisiva na formação de raízes, e o grupo desses reguladores mais utilizado é o das auxinas (HINOJOSA, 2000). Umas das formas de aplicação exógena de auxina, com intuito de possibilitar aumento da capacidade de enraizamento de estacas de espécies de difícil enraizamento, é a utilização do ácido indolbutírico (AIB). O AIB é a auxina mais comumente utilizada na indução do enraizamento adventício (VILLA et al., 2003) das estacas das mais diversas culturas.

Ao testar épocas de coleta de estacas e concentrações de AIB em duas cultivares do grupo rabbiteye, Hoffmann et al. (1995) constataram que a primavera é a época que permite obter maior porcentual de estacas enraizadas e as doses de 2000 e 4000 de AIB, foram mais adequadas para estimular o enraizamento. Mainland (1966) também cita que o melhor enraizamento de estacas de mirtilo é obtido quando os ramos são coletados após o primeiro fluxo de crescimento, na primavera.

Entre os fatores que afetam a formação de raízes adventícias em estacas, a lesão na base pode contribuir no índice de enraizamento. Essa lesão permite que ocorra maior absorção de água e de reguladores de crescimento (FACHINELLO et al., 2005), embora os resultados dessa técnica sejam variáveis. Outro fator condicionado ao enraizamento é o tipo de estaca utilizada: herbácea, semiherbácea e lenhosa (FACHINELLO et al., 2005), e as diferentes respostas das cultivares ao enraizamento de estacas, independente da espécie (TREVISAN et al., 2000).

Os fatores que influenciam o enraizamento de estacas são bastante variáveis e sua atuação pode se dar de maneira isolada ou por interação com os demais. Objetivou-se, no presente trabalho, testar o efeito do ácido indolbutírico e a lesão na base das estacas herbáceas, em diferentes cultivares de mirtilo (Vaccinium $\mathrm{sp}$.).

\section{MATERIAL E MÉTODOS}

Ramos da estação de crescimento vegetativo de plantas de mirtilo, com 23 anos de idade, das cultivares Florida, Woodard, Bluegem, Bluebelle, Clímax e Brite Blue, conduzidas na Embrapa Clima Temperado, Pelotas RS, localizada na Latitude $31,5^{\circ}$ e longitude $52,21^{\circ}$ à 70 metros de altura, foram coletados, preparados e conduzidos, em fevereiro de 2005, de acordo com o objetivo proposto nos experimentos descritos a seguir.

\section{Experimento 1}

Foram utilizadas estacas herbáceas com aproximadamente $12 \mathrm{~cm}$ de comprimento das cultivares Florida, Woodard, Bluegem, Bluebelle, Clímax e Briteblue. Foi feito um corte horizontal da base e em bisel na extremidade superior, com duas folhas, cortadas ao meio. Com auxílio de um canivete de enxertia, realizou-se a lesão na base da estaca. Posteriormente, as estacas foram tratadas com ácido indolbutírico, diluído em álcool etílico a $96^{\circ}$, na concentração 2000mg. $\mathrm{L}^{-1}$ e sem AIB, (água destilada) imergindo $2 \mathrm{~cm} \mathrm{da}$ base durante 15 segundos e colocadas para enraizar em caixas plásticas, contendo como substrato composto de areia e terra, em casa de vegetação sob nebulização intermitente, com temperatura média de $25^{\circ} \mathrm{C}$, durante 90 dias. Decorrido esse período , avaliou-se a porcentagem de estacas enraizadas, vivas sem raiz e mortas. $\mathrm{O}$ delineamento experimental utilizado foi inteiramente casualizado, com três repetições e cada unidade experimental composta por 5 estacas, perfazendo um fatorial $2 \times 2 \times 6$, sendo o fator técnica representado por dois níveis (com e sem lesão na base da estaca), o fator AIB por dois tipos (com e sem AIB) e o fator cultivar, representado por seis materiais genéticos (Florida, Woodard, Bluegem, Bluebelle, Clímax e Brite Blue).

\section{Experimento 2}

Estacas herbáceas das cultivares Clímax, Bluebelle e Briteblue foram preparadas com aproximadamente $12 \mathrm{~cm}$ de comprimento, com um corte horizontal da base e em bisel na extremidade superior, com folhas cortadas ao meio. Posteriormente, as estacas foram tratadas com ácido indolbutírico, diluído em álcool etílico a $96^{\circ}$, nas concentrações de zero, 2500, 5000 e 7500 mg.L - $^{-1}$ de AIB, imergindo $2 \mathrm{~cm}$ da base durante 15 segundos e colocadas para enraizar em caixas plásticas contendo como substrato composto de areia e terra, em casa de vegetação sob nebulização intermitente, com temperatura média de $25^{\circ} \mathrm{C}$, durante 90 dias. Decorrido esse período avaliou-se a porcentagem de estacas enraizadas. O delineamento experimental utilizado foi inteiramente casualizado, com quatro repetições e cada unidade experimental composta por 12 estacas, perfazendo um fatorial $3 \times 4$, sendo o fator cultivar, representado por três materiais genéticos (Bluebelle, Clímax e Brite Blue), e o fator AIB por quatro concentrações (zero, 2500, 5000 e 7500 mg. $\mathrm{L}^{-1}$ ). 
Os dados foram submetidos à análise de variância e as médias ao teste de Duncan, a 5\%. As análises foram processadas pelo programa SANEST. Os dados relativos a porcentagem, foram transformados para arc sen $\sqrt{\mathrm{x} / 100}$.

\section{RESULTADOS E DISCUSSÕES}

\section{Experimento 1}

De acordo com a análise da variância, observou-se que houve diferença significativa entre as cultivares avaliadas na porcentagem de enraizamento das estacas (Figura 1A).

Esse resultado denotou a diferença de potencial que as cultivares têm em emitirem raízes adventícias, e que o regulador de crescimento, $\mathrm{AIB}$, não teve efeito significativo, bem como a interação dos fatores. Esse efeito negativo do AIB na formação de raízes adventícias também foi observado por Wagner Junior et al. (2004). Entretanto, o porcentual de enraizamento das cultivares estudadas pelos autores foi em torno de $50 \%$ maior que os encontrados nesse trabalho. Isso denota que a resposta ao enraizamento das estacas pode diferir entre os anos, provavelmente pelos tratos culturais empregados, como nutrição e irrigação, que são de fundamental importância na manutenção do vigor da plantamãe, o que irá refletir na qualidade dos propágulos vegetativos (XAVIER et al., 2000). Kossuth et al. (1981) já relatavam a existência da diferença do potencial de enraizamento entre as cultivares de mirtilo.

Entre as cultivares avaliadas, a Clímax não apresentou emissão de raízes adventícias nas estacas, obtendo mais de $90 \%$ de estacas mortas (Figura 1B). Nesse aspecto diferiu dos resultados de Wagner Junior et al. (2004) que obtiveram $56 \%$ de enraizamento, e de Hoffmann et al. (1995), com 40\% de estacas enraizadas na mesma cultivar, Clímax. Nesse trabalho, provavelmente a dose do fitoregulador de $2000 \mathrm{mg} \mathrm{L}^{-1}$, não tenha sido suficientemente capaz de causar estímulo à formação de raízes adventícias, para essa cultivar.

Apesar das estacas terem sido colhidas no período de alta atividade meristemática e baixo grau de lignificação (fevereiro), vários fatores podem ter influenciado no baixo porcentual de enraizamento, pois, no período, foi registrada pouca precipitação pluviométrica $(4,4 \mathrm{~mm}$ no mês que antecedeu a coleta das estacas), interferindo assim na condição fisiológica da planta matriz, no teor de reservas e de nutrientes.

Em relação à lesão realizada na base das estacas, com o intuito de estimular a divisão celular e promover a formação de primórdios radiculares, verificou-se que ela não contribuiu para um maior enraizamento, independentemente da cultivar e da concentração do regulador de crescimento utilizado (Figura 1C). Esses resultados estão de acordo com os encontrados por Bastos et al. (2005) que, ao realizarem lesões em estacas de caramboleira, não verificaram benefícios da técnica no estímulo de formação de raízes. Da mesma maneira não foi verificado tal efeito no trabalho realizado por Wagner Junior et al. (2004), em cultivares de mirtilo. Porém, tem-se observado que, ao se efetuar lesão na base das estacas de mirtilo, ocorre uma necrose intensa na região do dano. Como nas estacas herbáceas, os primórdios radiculares surgem entre e fora dos feixes vasculares, com a necrose estabelecida, essa impede o processo de diferenciação, reduzindo e anulando a emissão de raízes adventícias.

\section{Experimento 2}

Não houve efeito significativo entre as cultivares na formação de raízes nas estacas (Tabela 1). Isso pode ser explicado, em parte, pelo fato de que o material poderia estar em pleno desenvolvimento, onde o balanço hormonal interno mostrava-se favorável ao enraizamento, ocorrendo, portanto uma resposta negativa às aplicações hormonais exógenas. Supõe-se que os níveis de auxina presente nas estacas herbáceas foram suficientes para a formação das raízes. Entretanto, as aplicações exógenas de reguladores de crescimento, principalmente auxinas, proporcionam maior porcentual, velocidade e qualidade para o enraizamento, embora as concentrações de reguladores de crescimento para o enraizamento a ser aplicado variem em função da espécie, do estado de maturação, das condições ambientais e da forma de aplicação (HARTMANN et al., 1997).

Para a porcentagem de estacas enraizadas, verificou-se que as cultivares Bluebelle e Briteblue obtiveram 50\% de enraizamento, já a cultivar Clímax obteve $19,8 \%$, caracterizando a diferença do potencial genético de cada cultivar em emitir raízes adventícias sem a intervenção do regulador de crescimento (Tabela 1) embora no experimento 1, a cultivar Clímax não tenha apresentado estacas enraizadas. Vários autores relatam a importância desse regulador, o AIB como promotor de enraizamento de estacas (FACHINELLO et al., 2005).

O método de propagação por estaquia pode proporcionar bons resultados, mas bastante variáveis com a cultivar. Hoffmann et al. (1995) ao realizarem a estaquia em novembro, obtiveram porcentuais de enraizamento próximos a $80 \%$ na cultivar Powder Blue e $40 \%$ com cultivar Clímax, e as concentrações de 2000 e 4000 mg.L.-1 foram as que proporcionaram melhores resultados.

Vários são os fatores que influenciam o enraizamento de estacas, e eles são bastante variáveis; sua atuação pode ocorrer de maneira isolada ou por interação com os demais. Assim, é necessário que se estude profundamente cada um desses fatores, tendo em vista que, com uma simples modificação em uma ou mais condições, pode-se viabilizar a propagação vegetativa de espécies consideradas de difícil enraizamento, como o mirtilo. 


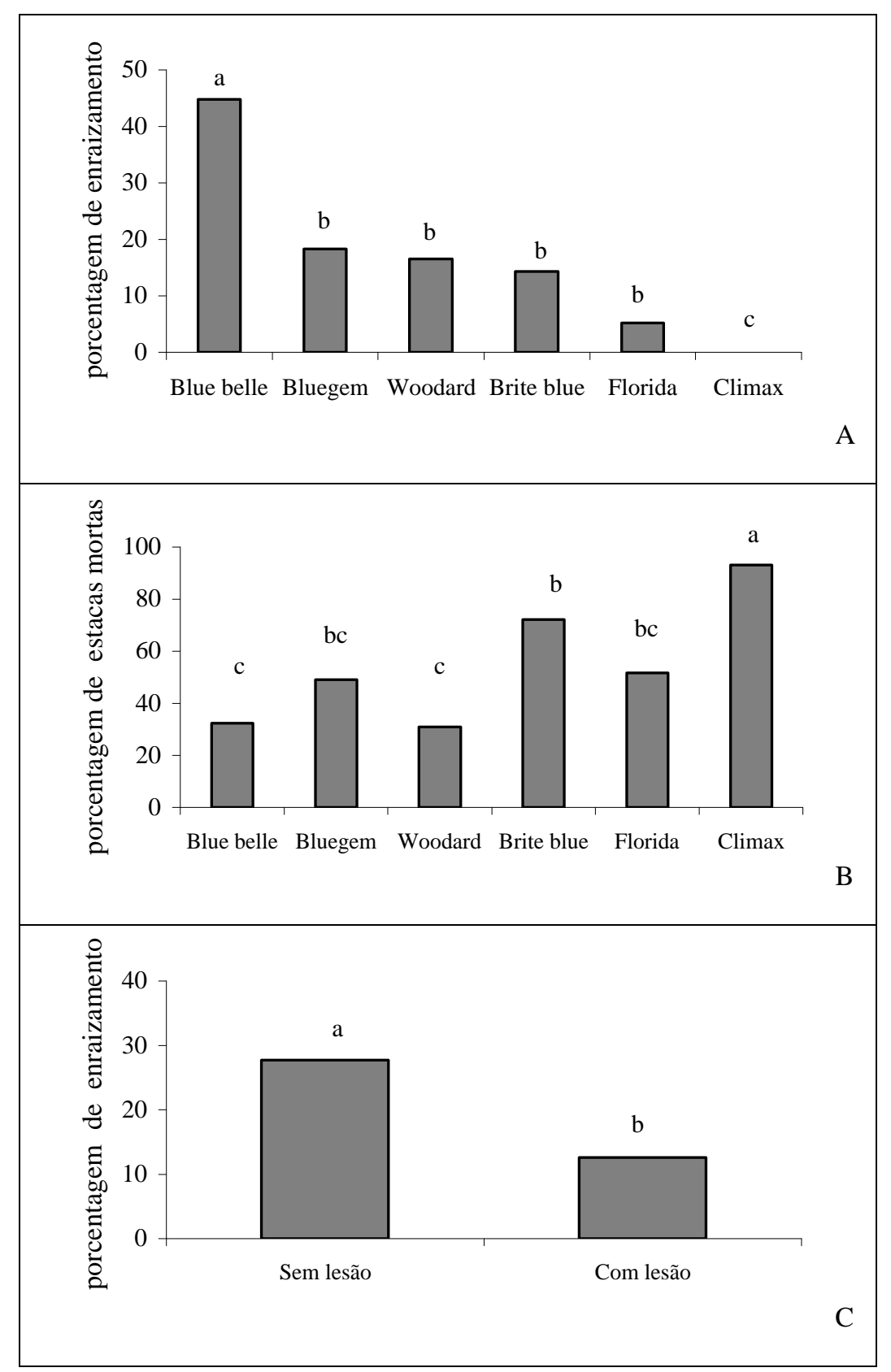

Figura 1 - Porcentagem de enraizamento de estacas herbáceas de diferentes cultivares de mirtilo (A), porcentagem de estacas mortas (B), porcentagem de estacas submetidas à lesão na base da estaca (C) e ao AIB. Pelotas, 2006. Médias seguidas pela mesma letra, não diferem pelo teste de Duncan, a 5\% de probabilidade. 
Tabela 1 - Porcentagem de estacas enraizadas de três cultivares de mirtilo, tratadas com diferentes concentrações de AIB. Pelotas, 2006.

\begin{tabular}{lc}
\hline Cultivares & Estacas enraizadas $(\%)$ \\
\hline Bluebelle & $51,6 \mathrm{a}$ \\
Brite blue & $50,9 \mathrm{a}$ \\
Climax & $19,8 \mathrm{~b}$ \\
\hline AIB $\left(\mathrm{mg.L}^{-1}\right)$ & \\
\hline Zero & $44,9 \mathrm{a}$ \\
2500 & $40,4 \mathrm{a}$ \\
7500 & $40,0 \mathrm{a}$ \\
5000 & $35,3 \mathrm{a}$ \\
\hline Média & 39,3 \\
CV $(\%)$ & 35,0 \\
\hline
\end{tabular}

Médias seguidas pela mesma letra não diferem entre si pelo teste de Duncan, a 5\% de probabilidade de erro.

\section{CONCLUSÕES}

De acordo com os resultados e as condições em que foram realizados os trabalhos, conclui-se que:

- o uso do ácido indolbutírico não proporcionou estímulo na emissão de raízes adventícias;

- a lesão na base das estacas com aplicação do ácido indolbutírico não influenciou no enraizamento das estacas herbáceas de mirtilo avaliadas;

- a cultivar Bluebelle apresentou maiores porcentuais de estacas enraizadas $(44,8 \%$ e $51,6 \%)$, e a Clímax, os menores porcentuais (zero e 19,8\%);

- as cultivares apresentam potencial genético de enraizamento diferenciado, e as cultivares classificaramse na seguinte ordem decrescente de enraizamento: Blue belle, Bluegem, Woodard, Brite blue, Florida e Clímax.

\section{AGRADECIMENTO}

À Fundação de Amparo à Pesquisa do Estado do Rio Grande do Sul (FAPERGS), pelo apoio financeiro dado ao projeto 04.0668.7, Procoredes I, e ao Conselho Nacional de Desenvolvimento Científico e Tecnológico e (CNPq) pela concessão de auxílio financeiro e bolsas de pesquisa (EV e PQ), aos autores do trabalho.

\section{REFERÊNCIAS BIBLIOGRÁFICAS}

BASTOS, D. C.; SCARPE FILHO, J. A.; FATINANSI, J. C.; PIO, R. Estiolamento, incisão na base da estaca e uso de AIB no enraizamento de estacas herbáceas de caramboleira. Revista Brasileira de Fruticultura, Jaboticabal, v. 27, n. 2, p. 281-284, 2005.
CHALFUN, N. N. J.; HOFFMANN, A. Propagação do pessegueiro e da ameixeira. Informe Agropecuário, Belo Horizonte, v. 18, n. 189, p. 23-29, 1997.

FACHINELLO, J. C.; HOFFMANN, A.; NACHTIGAL, J. C. Propagação de plantas frutíferas. Brasília, DF: [s.n.], 2005. 221 p.

HARTMANN, H. T.; KESTER, D. E.; DAVIES JUNIOR, F. T.; GENE, T. L. Plant propagation: principles and practices. New Jersey: Prentice-Hall, 1997. 770 p.

HOFFMANN, A.; FACHINELLO, J. C.; SANTOS, A. M. dos. Propagação de mirtilo (Vaccinium ashei Readi) através de estacas. Pesquisa Agropecuária Brasileira, Brasília, v. 30, n. 2, p. 231-236, 1995.

HINOJOSA, G. F. Auxinas. In: CID, L. P. B. Introdução aos hormônios vegetais. Brasília, DF: Embrapa, 2000. p. 15-54.

KOSSUTH, S. V.; BIGGS, R. H.; WEBB, P. G. Rapid propagation techniques for fruit crops. Proceedings of Florida State Horticulturae Society, Lake Buena Vista, v. 94, p. 323-328, 1981.

MAINLAND, C. M. Propagation and planting. In: ECK, P.; CHILDERS, N. F. Blueberry culture. New Brunswick: Rutgers University, 1966. p. 111-131.

STRICK, B. Chronica horticulturae. Blueberry: An expanding world berry crop. Belgium, v. 45, n. 1, p. 7-12, 2005.

TREVISAN, R.; SCHWARTZ, E. L.; KERSTEN, E. Capacidade de enraizamento de estacas de ramos de pessegueiros (Prunus persica ( L). Bastch) de diferentes cultivares. Revista Científica Rural, Bagé, v. 5, n. 1, p. 29-33, 2000.

VILLA, F.; PIO, R.; CHALFUN, N. N. J.; GONTIJO, T. C. A.; DUTRA, L. F. Propagação de amoreira-preta utilizando estacas lenhosas. Ciência e Agrotecnologia, Lavras, v. 27, n. 4, p. 829-834, 2003.

WAGNER JÚNIOR, A.; COUTO, M.; RASEIRA, M. do C. B.; FRANZON, R. C. Efeito da lesão basal e do ácido indolbutírico no enraizamento de estacas herbáceas de quatro cultivares de mirtilo. Revista Brasileira de Agrociência, Pelotas, v. 10, n. 2, p. 251-253, 2004.

XAVIER, A.; SANTOS, G. A. dos; WENDLING, I.; OLIVEIRA, M. L. de. Propagação vegetativa de cedro rosa (Cedrela fissilis) por miniestaquia. Revista árvore, Viçosa, v. 24, n. 2, p. 181-186, 2000. 